\title{
Repeated Sprint Ability of Youth Football Players in the Same Age Category According to Playing Position and Competition Level
}

\author{
Onat Çetin' ${ }^{1}$, Mehmet Koçak² \\ Affiliations: 'Yalova University, Faculty of Sport Sciences, Yalova, Turkey, ${ }^{2}$ Hitit University, Faculty of Sport Sciences, Çorum, Turkey
}

Correspondence: O. Çetin, Yalova University, Faculty of Sport Sciences, Yalova Üniversitesi Merkez Yerleşkesi, Çınarcık Yolu Üzeri 77200 Yalova, Turkey. E-mail: onat.cetin@yalova.edu.tr

\begin{abstract}
This study aims to examine repeated sprint performances of young soccer players in the same age category according to competition level and playing positions. 67 young soccer players in the U16 age category and from 4 different teams competing in two different competition levels participated voluntarily in this study. The participants performed the Bangsbo Sprint Test adapted by Wragg ( $7 \times 34,2 \mathrm{~m}$ with 25 -second recovery) to determine repeated sprint performance. The test variables were best sprint time, mean sprint time, and the fatigue index. The best sprint time and mean sprint time results varied according to competition level $(p<0,05)$ but the fatigue index did not differentiate according to competition level $(p>0,05)$. It is also determined that at a high competition level players have revealed better-repeated sprint performance. When examined the data in terms of game position, best sprint time and mean time values have varied $(p<0,05)$ but the fatigue index did not have significant differences $(p>0,05)$. Considering the data according to game positions, forwards, full-backs and wingers showed higher performance than central midfielders, central defenders, and goalkeepers. Consequently, our results suggest that performance in repeated-sprint the best sprint values and mean sprint values belonging to repeated performances of youth players from the same age category differ according to competition levels and game positions, whereas the fatigue index does not differ.
\end{abstract}

Keywords: repeated sprint ability, age category, competition level, playing position

@MJSSMontenegro

REPEATED SPRINT ABILITY OF YOUNG FOOTBALL PLAYERS

http://mjssm.me/?sekcija=article\&artid=232

Cite this article: Çetin, O., \& Koçak, M. (2022). Repeated Sprint Ability of Youth Football Players in the Same Age Category According to Playing Position and Competition Level. Montenegrin Journal of Sports Science and Medicine, 11(1), 59-63. https://doi. org/10.26773/mjssm.220307

\section{Introduction}

The workload rate of the football player during matches' ranges from low-level activities such as walking and jogging to high-intensity activities such as sprinting (Abrantes et al., 2004). In addition, today's football has become faster than in the past in terms of the speed of the ball passing from player to player and the player's movements (Jeffreys \& Bate, 2015). Football match anal- ysis studies showed that football requires the ability to perform repeated maximal or submaximal short-term actions with short recovery periods (Bravo et al., 2008). Due to the repetitive occurrence of sprints before sufficient recovery time during football matches, successive sprint performance deteriorates. Thus, one of the most important conditioning features of an athlete in team sports is the ability to perform sprint runs with short recovery in-

Received: 17 December 2021 | Accepted after revision: 18 January 2022 | Early access publication date: 7 February 2022 | Final publication date: 1 March 2022 (c) 2022 by the author(s). License MSA, Podgorica, Montenegro. This article is an open access article distributed under the terms and conditions of the Creative Commons Attribution (CC BY).

Conflict of interest: None declared. 
tervals, which is called repeated sprint ability (Mujika et al., 2009; Spencer et al., 2006; Spencer et al., 2004). Repeated sprint ability is an important team sport component that requires athletes to produce irregularly split maximal and submaximal short sprints with incomplete recovery periods throughout the match (Barbero-Álvarez et al., 2013). Therefore, the ability to repeat multiple sprints is important for the physical performance of the football player, and accordingly, the use of repeated sprint exercises and tests is increasing day by day (Impellizzeri et al., 2008).

Even though the sprint distance in the football game is less than $10 \%$ of the total distance covered, it is one of the most important performance variables. The result of a football match may depend on a player performing a sprint faster than their opponent (Abrantes et al., 2004). The result of a football match may depend on a player performing a sprint faster than their opponent. Speed in football can differ not only according to other sports but also according to the playing positions, and speed is a valuable performance component in football for every position except the goalkeeper (Gatz, 2009). Past researches stated that in team sports, sprints occur repeatedly before the recovery period is complete, and therefore sprint performance may be impaired (Falk \& Dotan, 2006). In addition, it has been reported that repeated sprint performances of young athletes differ from adults due to shorter physiological recovery times after repeated sprint runs (Abrantes et al., 2004; Mendez-Villanueva et al., 2011; Mujika et al., 2009). In addition, in the studies conducted with simultaneous athlete tracking systems, it is stated that the performance and frequency of repetitive sprints in match activity vary according to age and playing position (Buchheit et al., 2010). However, there are very limited studies examining the repeated sprint performances of young football players in the same age category according to their playing positions and competition level.

Every year, millions of young football players in different parts of the world participate in the development programs of football clubs. Determining the level of important performance components according to the positions, and competition levels of young football players are very important for talent selection, evaluation of physical fitness, and developing long-term training for their development. Therefore, this research aims to examine the repeated sprint ability performances of young football players in the U16 age group according to their competition level and their playing positions.

\section{Methods \\ Subjects}

A total of 67 youth football players (age $=15.6 \pm 0.38$ years; weight $=62.18 \pm 7.45 \mathrm{~kg}$; height $=173.22 \pm 6.38 \mathrm{~cm}$ ) playing football in the U16 age category of 4 teams (2 professional and 2 amateur) participated in the study voluntarily. 31 of these athletes play in the local amateur leagues and 37 of them play football in the development league, which is a higher league. Written informed consent was obtained from the players and their parents. In the interviews with the team leaders, it was determined that all of the athletes train 4-5 times a week and for 70-100 minutes.

\section{Study design}

All measurements of the research were taken during the competition period. 4 different measurement days were determined for 4 different teams. The repeated sprint test was applied on the synthetic grass and at least 2 days after the official competitions, while the athletes were recovered. All performance tests were performed in an outdoor facility maintained at standard environmental conditions. The tests were conducted during the day between 15:00 and 17:00. Height and weight measurements were taken between 10:00 and 11:00 in the morning. Since all the teams played almost all of their matches on synthetic grass, synthetic turf was chosen as the testing ground. Attention was paid to the fact that the athletes followed the same diet in their meals before the tests. This study was approved in advance by Gazi University Ethics Committee (Approval number: 77082166-604.01.02). Each participant voluntarily provided written informed consent before participating.

\section{Repeated sprint test}

The Bangsbo Sprint Test adapted by Wragg et al. was used to determine the repeated sprint ability performances of the participants. The Bangsbo Sprint Test protocol consists of 7 maximal sprints of $34.2 \mathrm{~m}$ each. The recovery between sprints is active and the athlete has $40 \mathrm{~m}$ to return to the start from the finish line and 25 seconds to run this distance at a slow pace (Pasquarelli et al., 2010). Since there is no generally accepted repetitive sprint test suitable for the intermittent nature of the football game, it is very difficult to determine the validity of these tests. However,

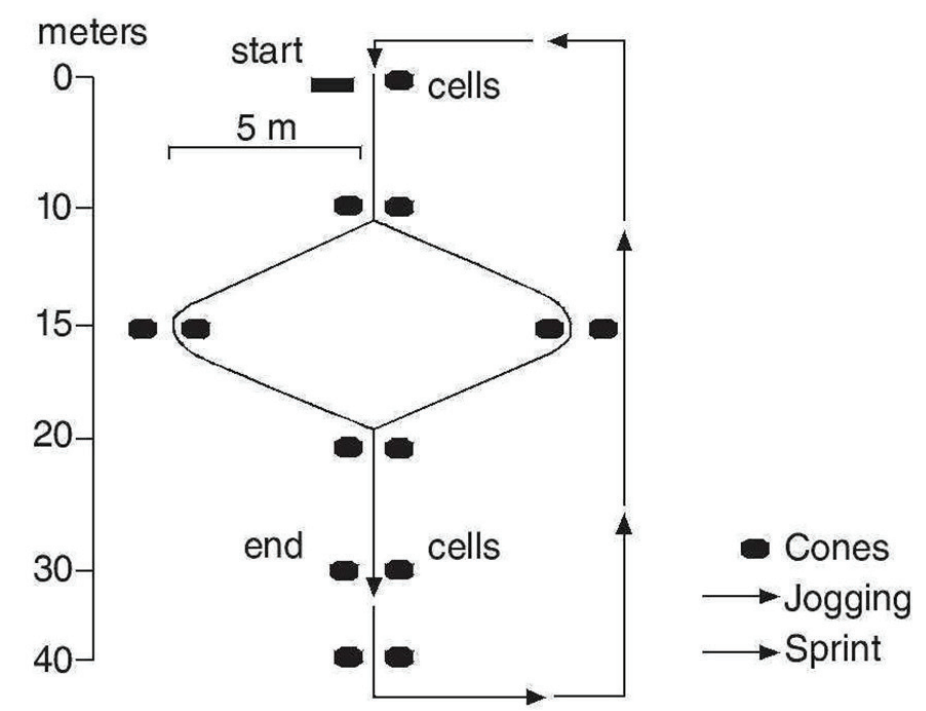

Figure 1. Schematics of Bansgsbo sprint test adapted by Wragg et al. (Pasquarelli et al., 2010) 
the $7 \times 34.2 \mathrm{~m}$ deflection sprint test is considered a valid test. The $7 \times 34.2 \mathrm{~m}$ change-of-direction sprint test was reliable because the coefficient of variation was $1.8 \%$ and it was in the $95 \%$ confidence interval (Wragg et al., 2000).

Before the test started, all participants performed a 20-minute warm-up that included general and test-specific activities. During the general warm-up part, the athletes performed low-intensity forward, sideways, and backward running, acceleration runs, skipping and hopping exercises, and jumps at increasing intensity. In the sprint part of the warmup, after the participants did $220 \mathrm{~m}$ sprints including passive rest, 1 sprint was made to gain predisposition on the test area. After each sprint during the test, the recovery section, which lasted 25 seconds and included $40 \mathrm{~m}$ low tempo running, was carefully followed and feedback was given to each of the athletes about the remaining time in the 10th and 20th seconds of the recovery time. During the test, the athletes were verbally encouraged. Each 7 sprint time was recorded in seconds by the photocells located at the start and finish lines. The best sprint time, average sprint time, and fatigue index parameters were calculated as a result of the repeated sprint test.

\section{Statistical analyses}

IBM SPSS Statistics 22.0 package program was used in the analysis of the obtained data. The normality test of the data was analyzed with the Shapiro-Wilk test. Non-parametric analysis methods were used because the measurement data were not suitable for normal distribution. Mann Whitney $U$ test was used to compare the best sprint and average sprint grades and fatigue index values according to competition levels, and the Kruskal Wallis $\mathrm{H}$ test was used to compare according to playing positions.

\section{Results}

As shown in Table 1. the best sprint and mean sprint times of young football players differ significantly according to the competition level $(\mathrm{p}<0.05)$, while the fatigue indexes do not differ significantly according to the competition levels ( $p>0.05)$. Development League players have better performances in all of the different sprint times (Table 1).

Table 1. Comparison of the Best Sprint, Mean Sprint, and Fatigue Index Values of the Players According to Competition Level

\begin{tabular}{|c|c|c|c|c|c|c|c|}
\hline Measures & Competition levels & $\mathbf{N}$ & $\mathbf{x}$ & ss & MR & $\mathbf{U}$ & $\mathbf{P}$ \\
\hline \multirow{2}{*}{ Best sprint time } & Devolopment league & 35 & 6,31 & 0,253 & 27,29 & \multirow{2}{*}{325,0} & \multirow{2}{*}{0,003} \\
\hline & Local amateur league & 32 & 6,46 & 0,210 & 41,34 & & \\
\hline \multirow{2}{*}{ Mean sprint time } & Devolopment league & 35 & 6,49 & 0,229 & 26,77 & \multirow{2}{*}{307,0} & \multirow{2}{*}{0,001} \\
\hline & Local amateur league & 32 & 6,65 & 0,203 & 41,91 & & \\
\hline \multirow{2}{*}{ Fatigue index } & Devolopment league & 35 & 3,33 & 1,499 & 35,67 & \multirow{2}{*}{501,5} & \multirow{2}{*}{0,463} \\
\hline & Local amateur league & 32 & 3,06 & 0,916 & 32,17 & & \\
\hline
\end{tabular}

As shown in Table 2, the best sprint, mean sprint times of the players differ significantly according to their playing positions $(\mathrm{p}<0.05)$. It was determined that the fatigue index data did not show a significant difference ( $p>0.05)$. The differences in the best sprint times are due to the times of the full backs and forward players being better than the centre backs, centre midfielders, and goalkeepers, while the central midfielders are better than the centre backs. The differences in the average sprint times are due to times of the full backs, wingers and forward players are better than the centre backs, centre midfielders and goalkeepers.

Table 2. Comparison of the Best Sprint, Mean Sprint, and Fatigue Index Values of the Players According to Playing Positions

\begin{tabular}{|c|c|c|c|c|c|c|c|}
\hline Measures & Playing positions & $\mathbf{N}$ & $\mathbf{x}$ & SS & MR & $\mathbf{x 2}$ & $\mathbf{P}$ \\
\hline \multirow{6}{*}{ Best sprint time } & Full back & 9 & 6,24 & 0,167 & 22,17 & \multirow{6}{*}{20,67} & \multirow{6}{*}{0,001} \\
\hline & Centre back & 11 & 6,56 & 0,197 & 48,36 & & \\
\hline & Winger & 11 & 6,33 & 0,240 & 30,32 & & \\
\hline & Centre midfielder & 17 & 6,47 & 0,239 & 40,94 & & \\
\hline & Forward & 13 & 6,20 & 0,138 & 19,46 & & \\
\hline & Goalkeeper & 6 & 6,52 & 0,269 & 44,00 & & \\
\hline \multirow{6}{*}{ Mean sprint time } & Full back & 9 & 6,43 & 0,168 & 22,39 & \multirow{6}{*}{24,97} & \multirow{6}{*}{0,000} \\
\hline & Centre back & 11 & 6,72 & 0,203 & 47,14 & & \\
\hline & Winger & 11 & 6,42 & 0,124 & 22,73 & & \\
\hline & Centre midfielder & 17 & 6,70 & 0,226 & 44,65 & & \\
\hline & Forward & 13 & 6,41 & 0,128 & 21,04 & & \\
\hline & Goalkeeper & 6 & 6,72 & 0,240 & 45,92 & & \\
\hline \multirow{6}{*}{ Fatigue index } & Full back & 9 & 3,22 & 1,140 & 34,89 & \multirow{6}{*}{8,4} & \multirow{6}{*}{0,136} \\
\hline & Centre back & 11 & 2,39 & 0,954 & 20,77 & & \\
\hline & Winger & 11 & 2,98 & 1,589 & 30,14 & & \\
\hline & Centre midfielder & 17 & 3,69 & 1,386 & 40,76 & & \\
\hline & Forward & 13 & 3,46 & 1,013 & 38,92 & & \\
\hline & Goalkeeper & 6 & 3,10 & 0,788 & 34,17 & & \\
\hline
\end{tabular}




\section{Discussion}

In this study, we examined the differences in repeated sprint ability performances' of young football players in the same age category (U16) according to competition level and playing positions. The main findings of the study showed that repeated sprint performances' of young football players differ according to competition level and playing positions, the fatigue index does not differ.

Although no research in the literature examined the repeated sprint performance of young football players in the same age according to the competition level, the studies conducted on adults and examining the repetitive sprint ability according to the competition level are in line with the results of this study. Rampinini et al. (2009) examined the repeated sprint abilities of 12 professional and 11 amateur football players playing at different standards and the relationship of this ability with factors such as intermittent running test, oxygen consumption, and maximal oxygen consumption. As a result, they determined that the repeated sprint ability and the responses of this ability to various physiological factors differ between professional and amateur football players. Abrantes et al. (2004) applied the Bangsbo sprint test to 146 football players playing in different competition levels and different age categories in their study and evaluated the repeated sprint ability performances of football players in three different competition levels. As a result of the study, National 1st League (top-level) players showed higher repeated sprint performance than players playing in other leagues. In addition, Aziz et al. (2008) examined the validity of the repeated sprint ability test between position and competition level in football players and determined that repeated sprint ability was superior in teams with high competition levels. In a systematic review that investigated measurement properties and feasibility of a repeated sprint ability test, the authors reported that repeated sprint performance can discriminate soccer players of playing positions (goalkeepers and outfields), competition levels (professional, amateur, and semi-professional) (Lopes-Silva et al., 2019). One of the important reasons why the performance of repeated sprint ability differs according to competition level in young football players is because the quality of training differs according to the competition level. In this study, players at two different competition levels were examined. Especially since the Development League has a longer league period than the local amateur leagues, young football players can train for longer periods. It is thought that this situation contributes more to the physical development of young football players and therefore to their repetitive sprinting abilities compared to players at lower league levels.

In the past studies that examined the repeated sprint performance according to the playing positions, the researchers stated variable results. In one study of 85 adult amateur football players, in which repeated sprint performance and fatigue index were examined according to player positions, no significant relationship was found between playing positions, contrary to our study (Kaplan, 2010). Similarly, Lockie et al. (2019) examined 18 adult football players and reported that repeated sprint performance did not differ according to playing positions. However, in these studies, position diversification was not as detailed as in this research (defenders, midfielders, and forwards). The progressive and changing tactical structure of the football game requires a more detailed examination of the players in terms of playing position. For example, as in our research, center-backs and full-backs showed different performance characteristics among defenders. In another study, Aziz et al. (2008) stated that forwards have higher repeated sprint ability performance compared to defenders and midfielders. Especially in today's football, which is played faster than in the past, the sprinting skills of the forward, full-backs, and winger players should be better than the players in other positions. Midfielders and central defenders, on the other hand, cannot find enough space for long-distance sprint runs due to their duties and positions on the field.

The results from this study showed that the fatigue index does not differ significantly according to the competition level and game positions. Although it was stated in the past studies that performance variables such as best sprint and average sprint provided sufficient absolute and relative reliability related to repeated sprint performance, low values were reported regarding the reliability of the fatigue index (CV: 14.4-52.0\%) (Glaister et al., 2008; Lopes-Silva et al., 2019). Researchers stated that this is due to the use of different formulas to calculate fatigue in repeated sprint tests. For this reason, the use of the fatigue index is a situation that should be questioned due to the lack of reliability (Oliver, 2009).

In conclusion, repeated sprint performance also increases in direct proportion to the fitness levels of the players in leagues with high training quality and frequency. By the changing needs and tactical structure of football, repeated sprint ability also varies between playing positions. Coaches and football professionals can use repetitive sprint ability data as one of the key indicators in talent selection, creating a longterm training program and in the distribution of tasks according to physical characteristics in the football team. Future longitudinal studies with large samples as different age categories, and competition levels are necessary in order to confirm these results.

\section{References}

Abrantes, C., Macas, V., \& Sampaio, J. (2004, Nov). Variation in football players' sprint test performance across different ages and levels of competition. Journal of Sports Science and Medicine, 3(YISI 1), 44-49. https://www.ncbi.nlm.nih. gov/pubmed/24778553

Aziz, A., Mukherjee, S., Chia, M., \& Teh, K. (2008). Validity of the running repeated sprint ability test among playing positions and level of competitiveness in trained soccer players. International journal of sports medicine, 29(10), 833-838. https://doi.org/10.1055/s-2008-1038410

Barbero-Álvarez, J., Pedro, R., \& Nakamura, F. (2013). Validity of a repeated-sprint ability test in young soccer players. Science \& Sports, 28(5), e127-e131. https://doi. org/10.1016/j.scispo.2012.12.003

Bravo, D. F., Impellizzeri, F. M., Rampinini, E., Castagna, C., Bishop, D., \& Wisloff, U. (2008). Sprint vs. interval training in football. International journal of sports medicine, 29(08), 668-674. https://doi.org/10.1055/s-2007-989371

Buchheit, M., Mendez-villanueva, A., Simpson, B. M., \& Bourdon, P. C. (2010, Oct). Repeated-sprint sequences during youth soccer matches. International Journal of Sports Medicine, 31(10), 709-716. https://doi. org/10.1055/s-0030-1261897

Falk, B., \& Dotan, R. (2006, Jul). Child-adult differences in the recovery from high-intensity exercise. Exercise and Sport Sciences Reviews, 34(3), 107-112. https://doi. 
org/10.1249/00003677-200607000-00004

Gatz, G. (2009). Complete conditioning for soccer. Champaign (IL): Human Kinetics.

Glaister, M., Howatson, G., Pattison, J. R., \& McInnes, G. (2008, Sep). The reliability and validity of fatigue measures during multiple-sprint work: an issue revisited. The Journal of Strength \& Conditioning Research, 22(5), 1597-1601. https://doi.org/10.1519/JSC.0b013e318181ab80

Impellizzeri, F., Rampinini, E., Castagna, C., Bishop, D., Bravo, D. F., Tibaudi, A., \& Wisloff, U. (2008). Validity of a repeated-sprint test for football. International journal of sports medicine, 29(11), 899-905. https://doi. org/10.1055/s-2008-1038491

Jeffreys, I., \& Bate, D. (2015). Soccer Speed. Champaign (IL): Human Kinetics.

Kaplan, T. (2010, Jun). Examination of repeated sprinting ability and fatigue index of soccer players according to their positions. The Journal of Strength \& Conditioning Research, 24(6), 1495-1501. https://doi.org/10.1519/ JSC.0b013e3181d8e8ed

Lockie, R. G., Moreno, M. R., Orjalo, A. J., Stage, A. A., Liu, T. M., Birmingham-Babauta, S. A., Hurley, J. M., Torne, I. A., Beiley, M. D., \& Risso, F. G. (2019). Repeated-sprint ability in Division I collegiate male soccer players: Positional differences and relationships with performance tests. The Journal of Strength \& Conditioning Research, 33(5), 1362 1370. https://doi.org/10.1519/JSC.0000000000001948.

Lopes-Silva, J. P., da Silva Santos, J. F., Abbiss, C. R., \& Franchini, E. (2019). Measurement properties and feasibility of repeated sprint ability test: a systematic review. Strength \& Conditioning Journal, 41(6), 41-61. https://doi.org/10.1519/SSC.0000000000000495

Mendez-Villanueva, A., Buchheit, M., Kuitunen, S., Douglas, A., Peltola, E., \& Bourdon, P. (2011, Mar). Age-related differences in acceleration, maximum running speed, and repeated-sprint performance in young soccer players.
Journal of Sports Sciences, 29(5), 477-484. https://doi.org/1 $0.1080 / 02640414.2010 .536248$

Mujika, I., Spencer, M., Santisteban, J., Goiriena, J. J., \& Bishop, D. (2009, Dec). Age-related differences in repeatedsprint ability in highly trained youth football players. Journal of Sports Sciences, 27(14), 1581-1590. https://doi. org/10.1080/02640410903350281

Oliver, J. L. (2009). Is a fatigue index a worthwhile measure of repeated sprint ability? Journal of science and medicine in sport, 12(1), 20-23. https://doi.org/10.1016/j. jsams.2007.10.010

Pasquarelli, B., Santos, A., Frisselli, A., Dourado, A. C., \& Stanganelli, L. C. R. (2010). Relationship between the Bansgsbo Sprint Test with sprint, agility, lower limb power and aerobic capacity tests in soccer players. Revista Andaluza de Medicina del Deporte, 3(3), 87-91.

Rampinini, E., Sassi, A., Morelli, A., Mazzoni, S., Fanchini, M., \& Coutts, A. J. (2009). Repeated-sprint ability in professional and amateur soccer players. Applied Physiology, Nutrition, and Metabolism, 34(6), 1048-1054. https://doi.org/10.1139/H09-111

Spencer, M., Fitzsimons, M., Dawson, B., Bishop, D., \& Goodman, C. (2006, May). Reliability of a repeated-sprint test for field-hockey. Journal of Science and Medicine in Sport, 9(1-2), 181-184. https://doi.org/10.1016/j. jsams.2005.05.001

Spencer, M., Lawrence, S., Rechichi, C., Bishop, D., Dawson, B., \& Goodman, C. (2004, Sep). Time-motion analysis of elite field hockey, with special reference to repeated-sprint activity. Journal of Sports Sciences, 22(9), 843-850. https:// doi.org/10.1080/02640410410001716715

Wragg, C. B., Maxwell, N. S., \& Doust, J. H. (2000, Sep). Evaluation of the reliability and validity of a soccer-specific field test of repeated sprint ability. European Journal of Applied Physiology, 83(1), 77-83. https://doi.org/10.1007/ s004210000246 